\title{
Assessment of Surface Runoff Change Due to Urbanization Growth in Heliopolis Basin
}

\author{
Ashraf M. Elmoustafa, Engy Samir Helmy \\ Irrigation and Hydraulics Department, Faculty of Engineering,Ain Shams University, Cairo, Egypt
}

\begin{abstract}
Due to continuous increase in population, many new communities have been established in Heliopolis basin, one of the main watersheds located east of Cairo. The main objective of the present study is to highlight and to analyze the change in surface runoff due to the change in land use in Heliopolis basin between years 1984 and 2009 using Landsat satellite data for the years 1984, 2006 and 2009 with the aid of Digital Elevation Models (DEM). The techniques utilized in this investigation involved a supervised classification of the Landsat images. Results showed that urban area located in Heliopolis basin has increased more than 30\% during the last 30 years which led to a decrease in infiltration rates and an increase in surface runoff depth.
\end{abstract}

Keywords: Arid Regions, Drainage, Heliopolis Basin, Remote Sensing, Urbanization

\section{Introduction}

Due to thecontinuous population pressure that Cairo suffers, many new communities have been established in the desert fringes east of Cairo, the capital of Egypt, since the late 1980's and are expanding more and more by time, such as New Cairo, El Shorouq andBadr cities, and soon there will be more settlements.Allof these communities are currently expanding over Heliopolis basin, one of the main watersheds east of Cairo that drains towards the Nile Delta and arecontributing to the recharge of the aquifer of this area.

This change in land use has various environmental impacts that can be observed at different stages of urban growth. Thechange in land useleads to a significant increase in impervious area, which increases surface runoff,not only increasesthe peak discharge that is responsible for local flooding,but alsodecreasesthe groundwater rechargeand affects the ground water quality(figure 1)[1].

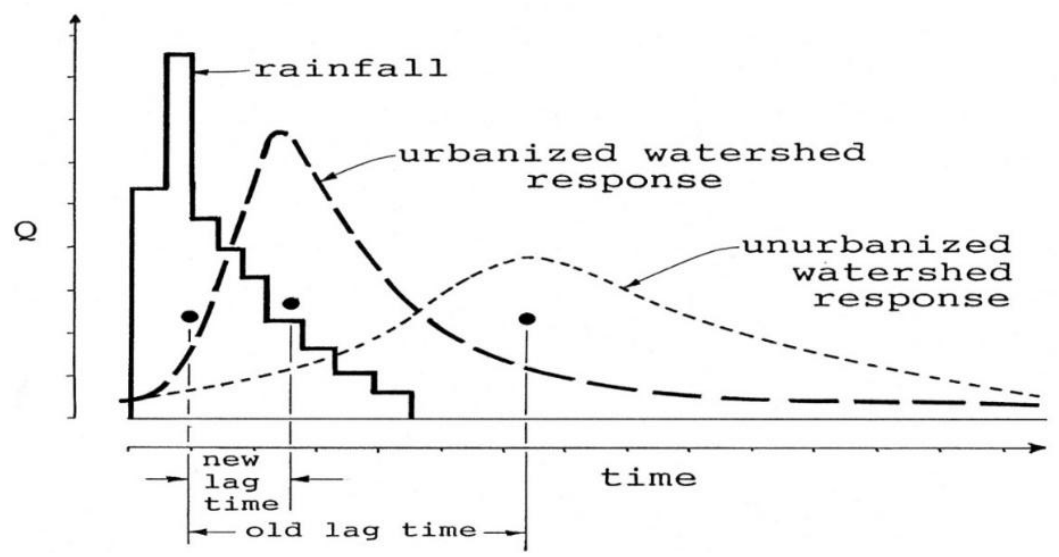

Figure 1: Impact of urbanization on storm water runoff rates and volumes [2]

The area under each curve represents the total volume of runoff. As it shows, the urbanization has higher peak discharge and more total runoff volume.

The study area is located East of Cairo(figure 2) and is bounded by latitudes $30^{\circ} 16^{\prime} 58$ " and $29^{\circ} 55^{\prime} 53^{\prime \prime}$ North and longitude $31^{\circ} 17^{\prime} 11$ " and $31^{\circ} 47^{\prime} 3$ " East, and it has a total area of $1,162 \mathrm{~km}^{2}$.Previous studies have investigated this area for groundwater exploration [3], geo-environmental studies using RS and GIS [4], and evaluation of groundwater resources change due to land use change using RS and GIS application and groundwater modelling [5].

The aim of this study is to investigate the occurring changes to the hydrological system of Heliopolis basin and to alert the community of potential long-term problems, already rising and are probably expected to increase more severely in the near future, and to provide possible solutions to reduce the impacts of this flooding. 


\section{Data Descriptionand Methodology}

The integration of Remote Sensing (RS) and Geographic Information Systems (GIS) has been widely applied and recognized as a powerful and effective tool in detecting urban growth [6]. This approach is also used to calculate the surface runoff volume $[7,8]$.

Figure 2 describes briefly the methodology adopted in the research progress that will be discussed thoroughly in this paper. The data (field and documented) were collected from different sources, mainly available on the internet, and then the data pre-processing took place to prepare it for the calculation. Finally, the results are interpreted for conclusion and recommendations.

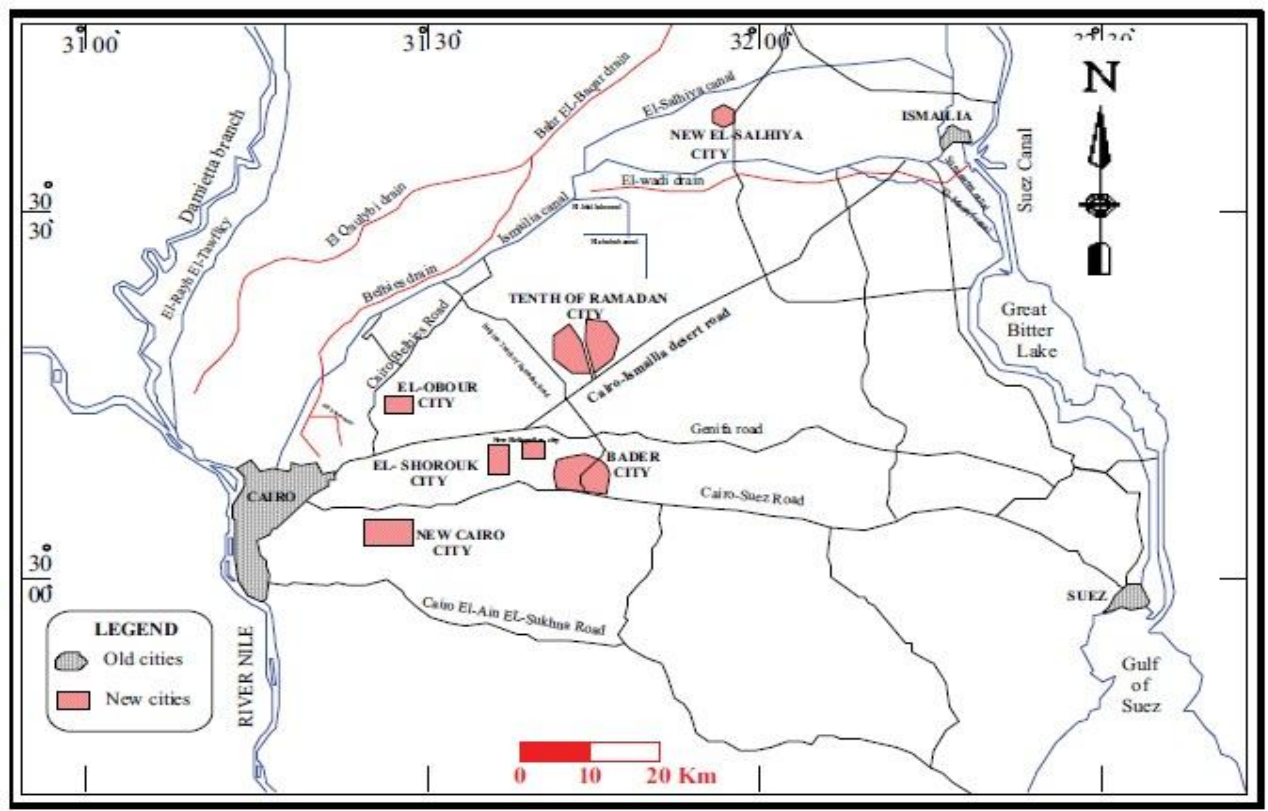

Figure 2: The new communities east of Cairo [3]

In order to accomplish the study objective, the following data were collected and processed.

Digital Elevation Model (DEM)

A Shuttle Radar Topography Mission Digital Elevation Model (SRTM DEM) from USGS (United States Geological Survey), with a resolution of $90 \mathrm{~m}$ at the equator, was used as a source for elevations to study the topography of the area, to define the flow paths and to delineate the main catchment for the study basin.

Soil type maps

In order to determine the different soil types in the study area,many references were used, such as the FAO/UNESCO Soil Map of the World at 1: 5,000,000 scale, which is available for free usage on the FAO website.

There was also a Cairo-Suez soil map at 1:200,000 scale, provided for free by EuDASM (European Digital Archive of Soil Maps). However,noneof them was used in this research because of their excessively large scale when compared to the study area.

Finally, a Landsat processed land cover dataset from (USGS) with 30m resolutionwas only used for visual guidance.

Satellite imageries

Satellite images of the USGSwere also used because of their easy accessibility, free cost and convenient resolution.There were 3 available satellite images for the study area captured during the last 30 years, representing the change in urbanization growth(figure 3). The first was taken by the Landsat thematic mapper (Landsat 5) in 1984. The other two were taken by the Landsat enhanced thematic mapper plus (Landsat 7) in 2006 and 2009(figure 6). All these images consist of spectral bands with a resolution of $30 \mathrm{~m}$ pixels. ArcGIS 9.3 by ESRI was used to combine different spectral bands to produce a raster dataset with false colours. The spectral bands combination (1, 4 and 7) was chosen to show clearly the urban areas. 

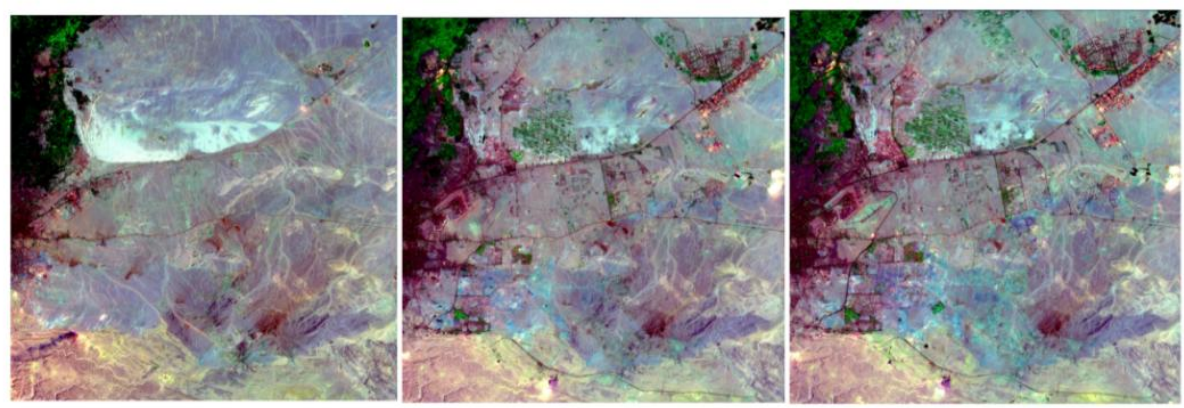

Figure 3: The three combined satellite images

\section{The Rainfall data}

For the Rainfall-Runoff calculations, the maximum daily rainfall data for 52 years (1961-2013)wereused(figure 4). These data werecollected from the Egyptian code of road design and the Egyptian Meteorological Authority (EMA) from Cairo airport station.

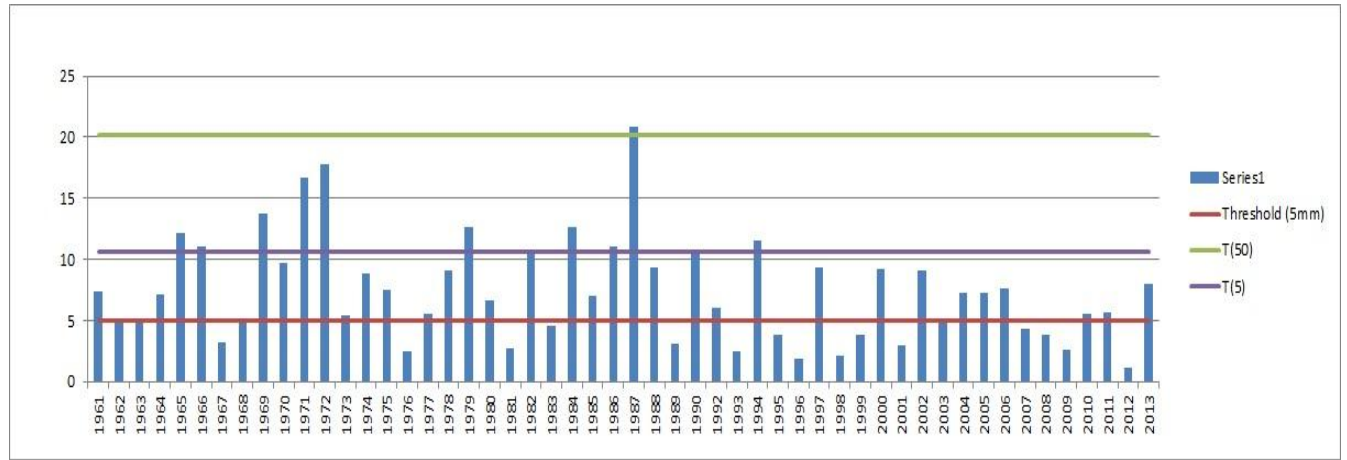

Figure4: Rainfall data (mm) for 52 years and the rainfall depths chosen for calculations

\section{Catchment delineation}

The goal of this step wasto develop the polygons (vector format data) representing the catchment and the sub-catchment from the available raster dataset. Processed by ArcGIS 9.3, the DEM was used to create a grid, in which each cell carries a value indicating to which catchment the cell belongs to by first computing the flow direction grid, then the flow accumulation grid and the stream definition grid. The result was 32 subcatchments representing Heliopolis basin(figure 5).

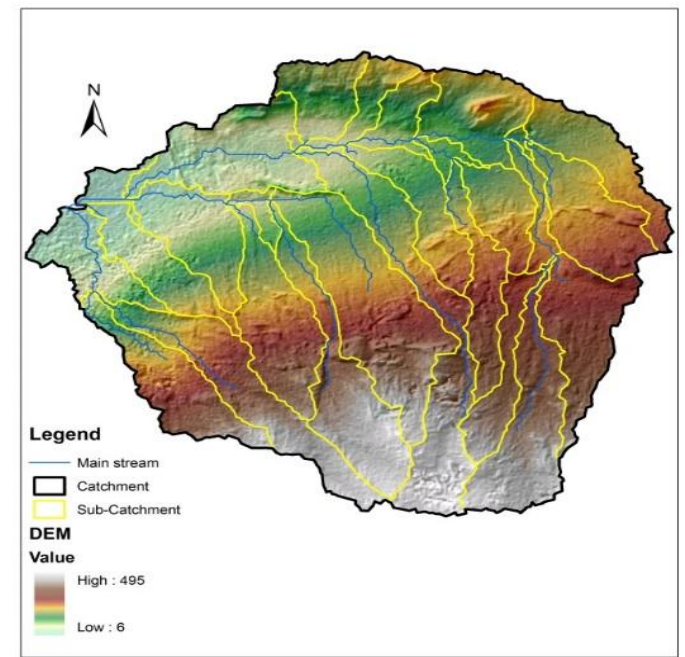

Figure5: Catchment delineation 
Despite all available data, none of them could be used to estimate the soil type because of their excessively large scale comparing to the study area. Eventually, the soil type of the study area was assumed based on a field visit with the guidance of previously mentioned maps. The soil could be classified belonging to different groups as those of the Soil Conservation Services (SCS) classification groups A, B, C, and D, as given in Appendix A published by the Soil Conservation Service (SCS) in the technical report 55 (TR-55) [9].

Land use grid production

ERDAS imagine 2013 was used to produce the land use raster maps with the help of the 3 satellite images mentioned aboveby applying a supervised classification on the combined raster.

The Curve number $(C N)$ grid

The runoff Curve Number $(\mathrm{CN})$ is a parameter used for predicting infiltration percentage from rainfall excess and hence the direct runoff. It depends on the watershed's soil type and cover conditions. It was developed by the U.S. Department of Agriculture (USDA) formally the U.S. Soil Conservation Service (SCS) in 1975.Using the estimated soil types and the land use classification from previous steps, CN can be determined using Technical Release No. 55 (TR-55) tables [9].In order to develop the $\mathrm{CN}$ grids, the land use grids were reclassified with the different $\mathrm{CN}$ values corresponding to each land class using an ArcGIS algorithm.

The Runoff Grid

After obtaining the CN Grid it becomes possible to calculate the runoff depth by applying SCS equation.

$\mathrm{Q}=\frac{(\mathrm{P}-0.2 \mathrm{~S})^{2}}{(\mathrm{P}+0.8 \mathrm{~S})}$

Where; $\mathrm{Q}=$ Runoff (inch), $\mathrm{P}=$ Rainfall (inch), $\mathrm{S}=$ Potential maximum retention runoff, $\mathrm{I}_{\mathrm{a}}=$ Initial abstraction (inch), andIa $=0.2 \mathrm{~S}$.

$\mathrm{S}=\frac{1000}{\mathrm{CN}}-10$

The rainfall data available for 1961-2013 and affecting the study area show that the data range between 1.2 $20.9 \mathrm{~mm}$ depth of rainfall.Data analyses were made in order to determine the 5, 10, 25, 50 and 100 years events. The 50 years event $(20.23 \mathrm{~mm})$ was chosen to produce the runoff grid.The potential infiltration grids were then used to estimate the runoff as per the SCS equations.

\section{ResultsandDiscussion}

Classification is a procedure used to interpret the observed data in an image into classified features through labelling each pixel to a particular spectral class. The supervised classification is a controlled procedure done by selecting recognized pixels with the help of other sources, such as field visit and existing maps, then training the computer system by selecting training samples to identify pixels with same characteristics applying the maximum likelihood algorithm to extract the classified raster.The spectral classes covering each land use category chosen were urban, desert and vegetation.

Figure 6 shows the change in the land use, how fast the urbanization grows, and the area statistics showing the exact percentage of growth. It is obvious that the urban area has grown by $30 \%$ over the 25 years, and by $15 \%$ only in the last 3 years.

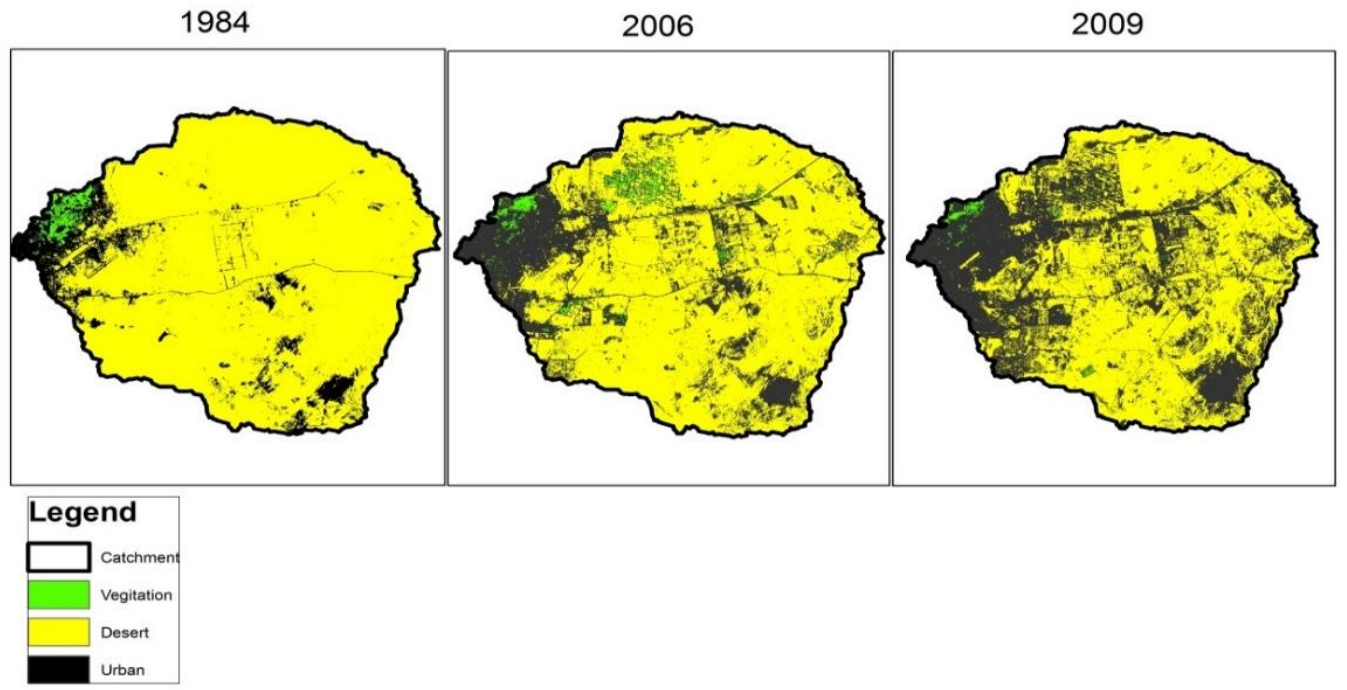

Figure 6: Change in land use over 25 years

Raster calculations were applied to the $\mathrm{CN}$ Grid first to estimate the potential infiltration grids (S Grid) using equation (2). The resulted grids show the effects of urbanization indecreasing the potential maximum retention(figure 7). 

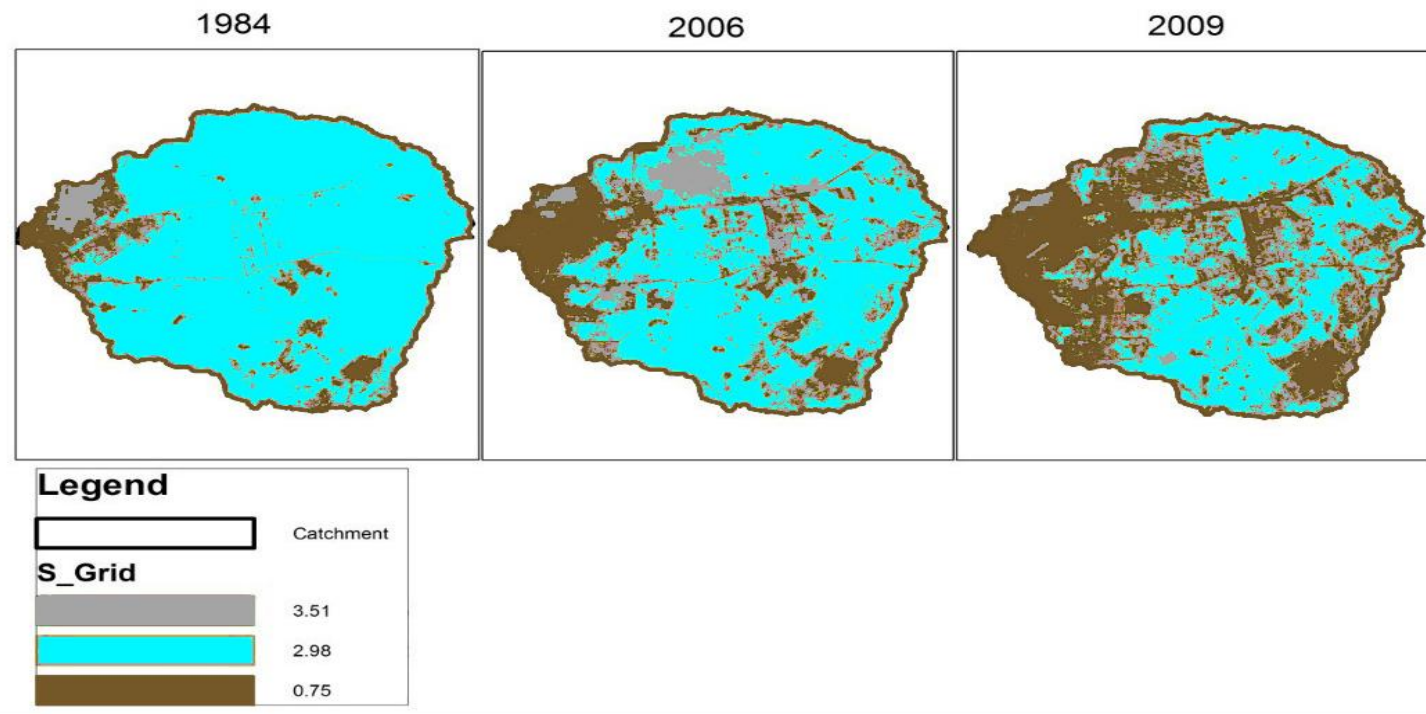

Figure 7: Potential infiltration grids

After applying the SCS equation using the 50 years event rainfall depth $(20.2 \mathrm{~mm})$ the runoff depth was finally estimated using equation (1). Figure 8 represents the runoff depth over each land use category. The runoff volume for each year was also calculated in order to study the increase in runoff volume due to the land use change (figure 9).

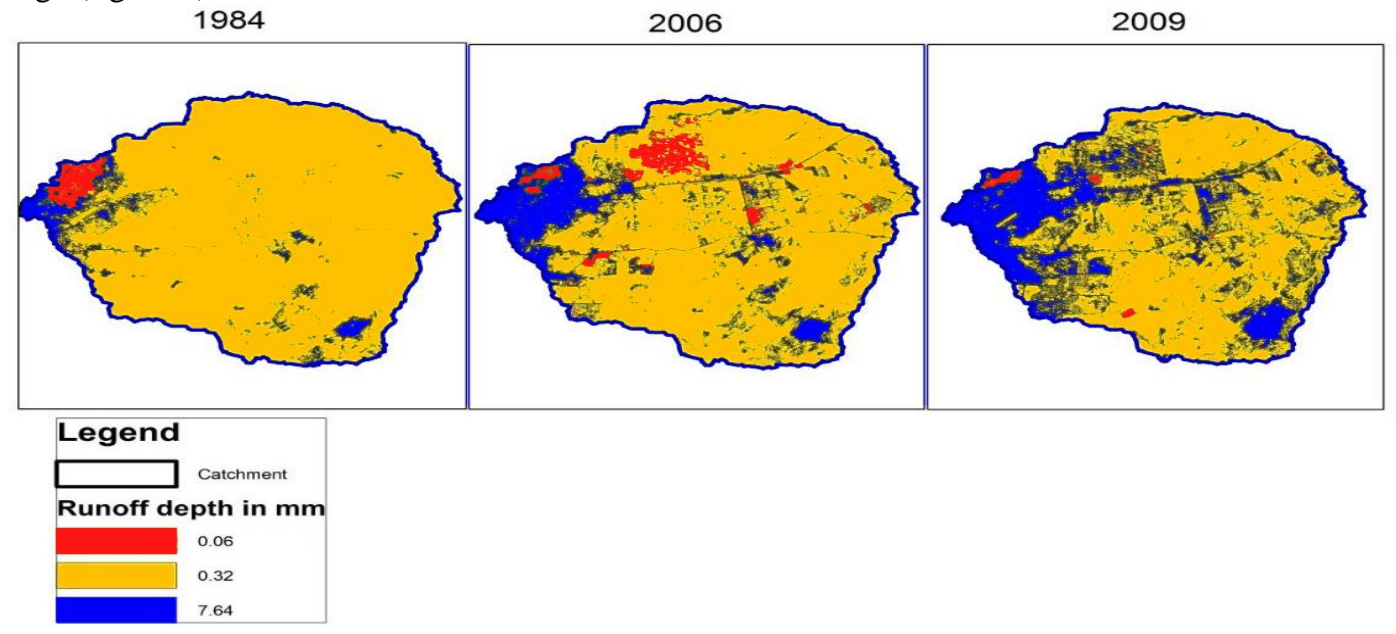

Figure 8: Runoff grids

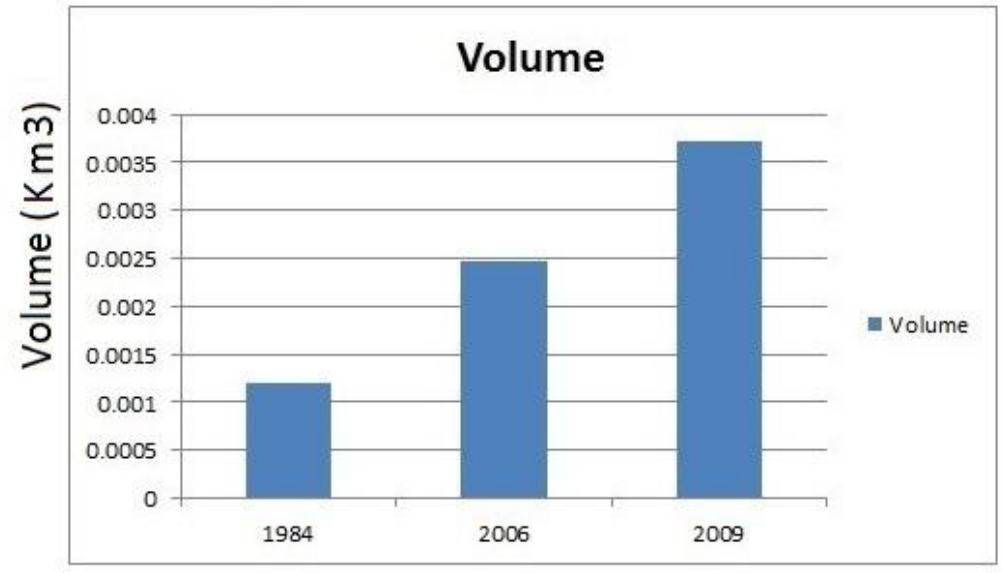

YEARS

Figure 9: Runoff volume in $\mathrm{km}^{3}$ 
Finally, the impacts of land-use on both surface runoff and infiltration rate were examined by comparing predicted potential infiltration and runoff depths of 1984 with those of 2009. Both grids of 1984 were subtracted from those of 2009. The resulting grids indicated that the potential infiltration was decreased and the runoff depth had increased by $7.3 \mathrm{~mm}$ which means that the runoff volume was increased by $2.5 \mathrm{Mm}^{3}(212 \%)$ during the 25years period due to land-use change(figure 10).
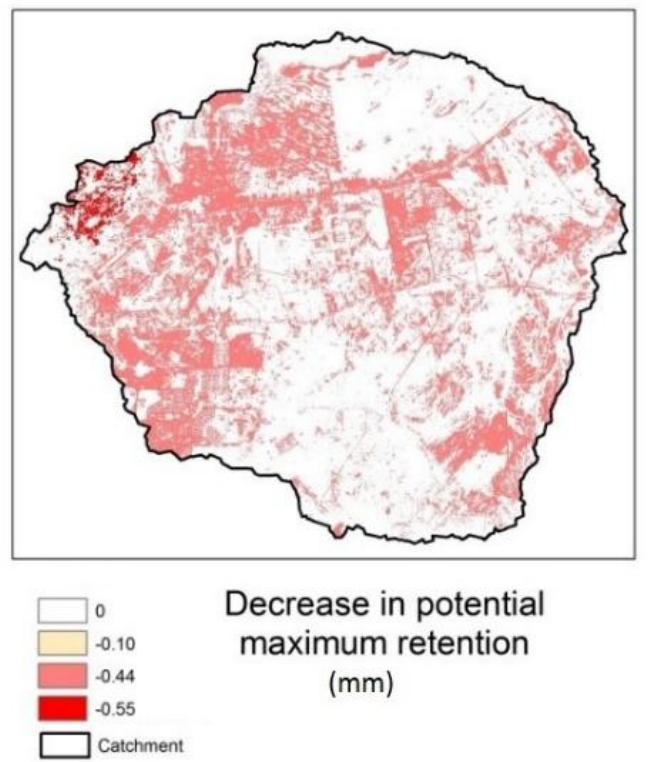

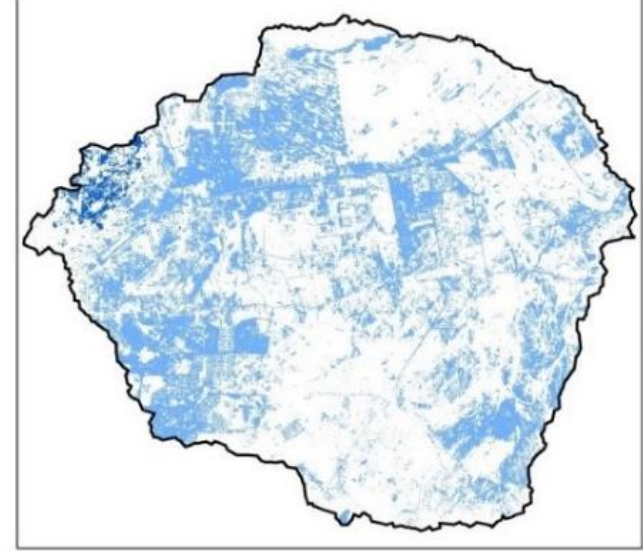

Increase in Runoff $(\mathrm{mm})$

Figure 10: Resulting grids from subtracting 1984 grids from 2009 grids

\section{Conclusions}

Due to continuous increase in population, many new communities have been established in Heliopolis basin, one of the main watersheds located east of Cairo. The urban area located in Heliopolis basin has increased more than $30 \%$ during the last 30 years which led to a decrease in infiltration rates and an increase in surface runoff depth. Apparently, this development has an immense impact on the hydrological situation at this area. In order to estimate the long-term effects on catchment basis, further studies should be conductedto investigate the soil type and land use classification assumptions to verify the results of this study.Links between this hydrological study and other groundwater studies should be established in orderto get more detailed results about the impactsof urbanization growth.Soil topography, hydrological and geological characteristics should be taken into consideration as well before planning new settlements.

\section{References}

[1] Harbor, J.M., A Practical Method for Estimating the Impact of Land-Use Change on Surface Runoff, Groundwater Recharge and Wetland Hydrology, J. American Planning Association 1994, 60, 95-108

[2] Burke, D., E. Meyers, R. Tiner, H. Gorma., Protecting non-tidal wetlands. American Planning Association, Planning Advisory Service, Report No. 412/413, 1988.

[3] El-Mahmoudi, A.S.; Shendi, E.H., Mohammed S.M., Groundwater Exploration with Schlumberger Soundings at Cairo-Bilbeis District, East Nile Delta, Egypt, UAEU Funded Research Publications, 2006, Vol. 15

[4] Abou El-Saoud, W.S.,Geo-environmental studies on new Cairo area and its vicinity, Egypt, using Remote sensing data and Geographic Information Systems. MSc thesis, Al-Azhar University, Cairo, Egypt, 2006.

[5] Abdelaziz, A.M., Applications of Remote Sensing, GIS, and Groundwater Flow Modelling in Evaluating Groundwater Resources: Two case studies; East Nile Delta,Egypt and Gold Valley, California, USA. PhD thesis, University of Texas at El Paso, 2007

[6] Dami A., Odihi J. O., Ayuba H. K., Assessment of Land use and Land Cover Change in Kwale, NdokwaEast Local Government Area, Delta State, Nigeria, Global Journal of Human-Social Science: B, Geography, Geo-Sciences, Environmental Disaster Management, 2014, 14(6), 17-24

[7] Weng, Q., Modelling Urban Growth Effects on Surface Runoff with the Integration of Remote Sensing and GIS, Environ. Manage. 2001, 28(6), 737-748

[8] Niehoff, D., Fritsch, U. and Bronstert, A., Land-use impacts on storm-runoff generation: scenarios of land-use change and simulation of hydrological response in a meso-scale catchment in SW-Germany, J. Hydrol. 2002, 267(1-2), 80-93

[9] U.S. Department of Agriculture, Natural Resources Conservation Services, Conservation Engineering Division, "Urban Hydrology for Small Watersheds - Technical Release No. 55", Second Ed., June 1986 